\title{
FARMER INNOVATIONS IMPROVING THE SYSTEM OF RICE INTENSIFICATION
} (SRI)

\author{
Norman Uphoff \\ Cornell International Institute for Food, Agriculture and Development (CIFAD), \\ Cornell University, Ithaca, New York USA
}

\begin{abstract}
The System of Rice Intensification (SRI), assembled in Madagascar over a 20-year period and gaining application internationally since 2000, enables farmers to raise their irrigated rice production substantially just by making changes in the way they manage their plants, soil, water and nutrients, rather than by increasing inputs such as fertilizer, water or agrochemicals. Getting more output with less cost enhances profitability. This result is quite unprecedented, as discussed in paper accompanying this one. SRI is not considered by its proponents as a technology; and by not presenting it to farmers as a set technology, this opens SRI up to many adaptations and innovations by farmer-users, who often but not always are collaborating with NGO or government staff in a collaborative manner. This paper reports on a number of the innovations that have been made in SRI practices, demonstrating both farmer capabilities and the advantages of engaging farmers as partners in an ongoing process of participatory development. The companion paper which considers SRI as a system for innovation offers a more 'macro' view of SRI spread that complements this more 'micro' perspective.
\end{abstract}

\section{INTRODUCTION}

SRI was not regarded as a technology either by its originator - Fr. Henri de Laulanié, S.J. $(1993,2003)$ - or by the NGO that he established with Malagasy friends in 1990 to disseminate its benefits, Association Tefy Saina. SRI was developed inductively, by observation and experiment, not shaped by any scientific theory or a priori reasoning. Accordingly, it has had difficulty gaining acceptance from 'mainstream' agricultural authorities, even though the evidence supporting it is strong and continues to accumulate. That SRI methods produce more output with less input makes it suspect in a world where we are told that there is 'no free lunch,' and where financial interests reinforce a focus on input-centered innovation.

SRI capitalizes on genetic potentials that already exist within the rice genome. These have, unfortunately, been inhibited or suppressed by sub-optimizing management practices for centuries. SRI methods yield more productive phenotypes because practically all genotypes of rice (Oryza sativa) respond positively to SRI practices, which achieve higher productivity of land, labor, capital and water, in large part by mobilizing the services of soil biota that can benefit plant health and growth (Randriamiharisoa et al., 2006). To be effective, soil organisms -- which range from microscopic to visible size -- require supportive conditions that enhance their abundance, diversity and activity: appropriate soil structure and conducive levels of soil organic matter, oxygen, temperature and moisture that, when within certain ranges, maintain the fertility and dynamics of soil systems (Uphoff $e t$ al., 2005).

Such conditions depend more upon knowledge and management than upon capital expenditure. Indeed, many of the practices based on capital and chemical inputs that have been introduced in the name of 'modern' agriculture have had negative effects on soil systems. Use of heavy machinery compacts the soil; plowing reduces the soil's organic matter and nitrogen stores; large applications of inorganic fertilizer and agrochemical crop protection alter the diversity and balance of species living within soil systems, making these ultimately less fertile, less resilient and more vulnerable to crop losses caused by pests and diseases.

Many farmers have some intuitive sense of this even if they do not have scientific knowledge to explain their observations. Fr. Laulanié did not set out to develop an 'organic' system of agricultural production. Initially he relied on chemical fertilizer together with the other practices that he had assembled because this was considered the best and quickest way to increase crop yields. Only when government subsidies for fertilizer were removed in the late 1980s did Laulanié start using compost. He discovered that it could give even better yields when used with the other SRI methods -- and at lower cost to the financially-constrained farmers with whom he worked. There are, however, times and places where some use of chemical fertilizer with SRI methods will be beneficial for farmers and compatible with soil-system health. So, SRI is a two-track system with 'organic SRI' being an important but not exclusive version of the original system. SRI is generally practiced with some reduction in chemical fertilizer and with an increase in organic fertilization. SRI is thus 'organic' only pragmatically rather than theoretically or normatively, being concerned with 'whatever works for farmers'.

This is the central theme of SRI: whatever works for the farmer. Farmers vary, of course, in terms of the sizes of their landholdings, the extent of their household labor supply, the characteristics of their soils, the amount and reliability of water available to support their crops, accessibility of markets for both input acquisition and sale of products, etc. There is no single standard 'farmer.' Proponents of SRI have thus resisted standardizing and thereby homogenizing SRI. Instead, they take satisfaction and find benefit in the diversity of applications to which the core ideas of SRI (reviewed below) have led. 
This has been a cause of some frustration, and even of some hostility, from scientists who want to reduce SRI to a fixed, invariant set of practices. However, SRI is what it is: something unusual in the history of agricultural innovation, a methodology that can produce more outputs from less inputs. Possibly it will give impetus for productive new thinking and new paradigms for agricultural development in general.

The proliferation of farmer contributions to improving SRI --and to adapting it to many different problems, different environments and even different crops - may be traced in large part to the novel nature of SRI. The discussion that follows documents some of the inventiveness of farmers for creating more and better opportunities to meet food security and livelihood needs, realizing that this if often done in cooperation with non- farmers, or with intermediaries who share farmers' aspirations.

\section{SRI CONCEPTS AND PRACTICES, PROBLEMS AND OPPORTUNITIES}

The System of Rice Intensification changes a number of practices that farmers have used for centuries, even millennia, to grow irrigated rice. However, it should be understood that $S R I$ is more than these practices. The concepts, ideas and principles preceding and justifying the practices are the crux of SRI. The alternative methods are manifestations of a different way of thinking about and pursuing agricultural production. The techniques that Fr. Laulanié put together (Uphoff, 2005), which represent operationally what has come to be known as SRI, can be summarized in Table 1.

Table 1. Comparison between conventional practice and SRI practice

Conventional practice

1. Transplant older seedlings, 20-30 days old, or even 40-60 days old in traditional practice

2. Transplant seedlings in clumps of plants and fairly densely, 50-150 plants per $\mathrm{m}^{2}$

3. Maintain paddy soil continuously flooded, with standing water throughout the growth cycle

4. Use water to control weeds, supplemented by hand weeding or use of herbicides

5. Use chemical fertilizers to enhance soil nutrient supplies
SRI practice

1. Transplant young seedlings, 8-12 days old, and certainly less than 15 days old; this preserves subsequent growth potential

2. Transplant seedlings singly, one per hill, and in a square pattern, $25 \times 25 \mathrm{~cm}$ ( 16 plants per $\left.\mathrm{m}^{2}\right)$ or wider if/when the soil is more fertile ${ }^{1}$

3. Keep paddy soil moist, but not continuously saturated, with intermittent drying, so that mostly aerobic soil conditions prevail

4. Control weeds with frequent weeding by a mechanical hand weeder (rotating hoe or cono weeder) that also aerates the soil

5. Apply as much organic matter to the soil as possible; can use chemical fertilizer with other SRI practices, but best results come from use of compost, mulch, etc.
Because SRI plants are more resistant to damage by pests and diseases, there is usually little or no need for agrochemical protection. SRI can thus be practiced without chemical inputs, although these can be used as an option. Undertaking SRI should be done in a spirit of pragmatism, rather than one of dogmatism. SRI is a strategy for mobilizing plant growth potentials, so it is really a matter of degree rather than of kind. One should ask: how much and how well are these different practices utilized? Instead of: whether SRI is being practiced or not? To what extent, and how well, are SRI practices (operationalizing SRI concepts) being followed? This is a better way to think and talk about SRI.

Because SRI practices are novel, and even counterintuitive, they often require more labor time when first taken up. SRI transplanting takes more time when farmers are first getting accustomed to handling tiny seedlings. But once farmers become more skilled and confident, the process goes more quickly and can even become labor- saving because SRI reduces plant populations by $80-90 \%$. Seed rate is only $--5 \mathrm{~kg} / \mathrm{ha}$ compared with $50 \mathrm{~kg}$ or more as in usual practice.

If farmers have not used the mechanical hand pushweeder (rotary hoe) before, they will find that it takes some time to become proficient and quick with this. SRI has a reputation for being labor-intensive -- indeed so laborintensive that this constitutes a barrier to adoption or a cause for disadoption (Moser and Barrett, 2003). However, evaluations in Cambodia (Anthofer, 2004), China (Li et al., 2005), India (Sinha and Talati, 2007), and Indonesia (Sato and Uphoff, 2007) have shown SRI methods to be laborneutral or even labor-saving. Farmers who have gained experience and facility with the new methods thus usually find that they can reduce their labor inputs within a season or two.

Even so, an important constraint that farmers have pointed to when questioned about SRI adoption has been labor requirements, and the fact that with SRI certain

\footnotetext{
'Also, seedlings should be transplanted quickly, replanting them within 15-30 minutes of being uprooted; shallow, only $1-2 \mathrm{~cm}$ deep; and gently, taking care to minimize any trauma to the roots. Plunging the seedlings down into the soil vertically inverts the roots tips, so that they point upwards and resumption of growth is delayed while the root tips get themselves reoriented downward. With SRI, seedling roots are to be slipped into the soil horizomally so their tips are not inverted up. This speeds resumption of growth.
} 
operations like transplanting and weeding are more 'timebound.' They should be done on a schedule set by the plant's growth requirements rather than farmer convenience. To get the most enhancement of production, the key SRI operations need to be performed in a timely way. Since transplanting is the most labor-intensive of the SRI operations, finding alternative methods of crop establishment has been attractive to many farmers. Also, given that there is growing evidence that standard tillage itself has negative consequences for soil systems, methods of establishing rice crops without tillage, i.e., zero-tillage or no-tillage, are of much interest to farmers.

One of the most attractive features of SRI is its reduction of water requirements for irrigated rice, by $25 \%$ or even $50 \%$ or more, when paddies are no longer kept continuously flooded (Satyanarayana et al., 2006). Farmers are quite eager to reduce they demand for water provided that labor requirements are not disproportionately increased relative to the benefits from using less water. There probably is scope for further reducing the water needs with SRI, since Laulanié's recommendations were entirely empirical, without systematic evaluation of alternative regimes. ' Thus far, there has not been much experimentation by farmers to test how much they can reduce water applications without curtailing yield. But in any case, being able to apply small amounts of water reliably on an as-needed basis is an objective need for SRI.

With SRI, there is also a premium placed on providing the soil with amendments of organic matter. Sometimes there is simply not enough supply of biomass available within the environment, e.g., when the climate is arid or semi-arid. However, often it is the labor required to acquire, transport, process and apply organic matter that is the constraint. Little research has been done on how to increase the supply of organic matter available for application in soils in an efficient manner, and there has been even less improvement over the past century in the tools and implements (cutters, shredders, wheelbarrows, etc.) that can make labor much more efficient for handling organic matter. This is an area where farmer ingenuity has not yet become very much engaged with SRI improvement.

For many crops and innovations, farmers need to be concerned with pests and diseases. However, as a rule SRI plants are less susceptible to damage and losses from these, because plants are more resistant (probably for reasons proposed by Chaboussou, 2004). Some farmers using SRI methods, particularly in India, are passionate supporters of organic means of pest and disease control, often linked to application of organic sources of nutrients. But so far, this has not been a matter of innovation so much as adopting ancient Vedic prescriptions for crop fertilization and

\footnotetext{
${ }^{1}$ The recommendation of alternate wetting and drying (AWD) up to the stage of panicle initiation (PI) -- but then keeping a thin layer of water (1-2 $\mathrm{cm}$ ) on the field until 20-30 days before harvest -- was probably a compromise by Laulanié, assuming that it would be too difficult to get farmers to.stop flooding their paddy field for the entire season. An NGO partner in southern India (Timbuktoo Collective) reports good SRI results by extending AWD throughout the whole season, with much saving of water. If plants' root systems have been well developed during the vegetative growth period (because fields have not been kept flooded), intermittent applications of water after PI should be sufficient, since there is usually water available in lower soil horizons that can be tapped by SRI plants' larger, deeper root systems.
}

protection. These seem to be efficacious, but they remain controversial among scientists and many farmers. What are reported here are innovations that have emerged in the course of SRI use and that have modified the potentials and applications of SRI beyond where it was 10 years ago, when the methods first started 'taking root' outside of Madagascar.

\section{FARMER INNOVATIONS}

\section{Nurseries}

While SRI is most often identified with transplanting of young seedlings -- the capstone innovation by Fr. Laulanié, which he reports was discovered by fortuitous accident some farmers even modifying this practice, by adapting direct seeding to SRI principles and practice, as discussed below. However, transplanting is still the first and most crucial step for most SRI farmers, and farmers are showing that there are a number of ways in which seedlings can be raised.

The conventional cultivation method is to grow seedlings densely planted in a flooded nursery or flooded portions of the main field. There are, however, very sound agronomic reasons for SRI's recommendation of a 'gardenlike' nursery with well-drained soil.

Farmers have developed different combinations of planting media for their nurseries. H.M. Premaratna in Sri Lanka uses equal proportions of soil, compost, and chicken manure because this mixture gives a non-sticky growth medium in which tiny, delicate seedling roots can be easily separated. Also, making nurseries as raised beds above the field level gives the soil more aeration, as Premaratna does using bamboo poles (Figure 1). A farmer innovation reported by Jessie Magsayo in North Cotabato, Philippines, is growing SRI seedlings in sand, since seedlings get most of their initial nutrients from the seed sac rather than the soil. It is very easy to separate seedlings grown this way, he says, so it is gaining favor among SRI farmers in his area.

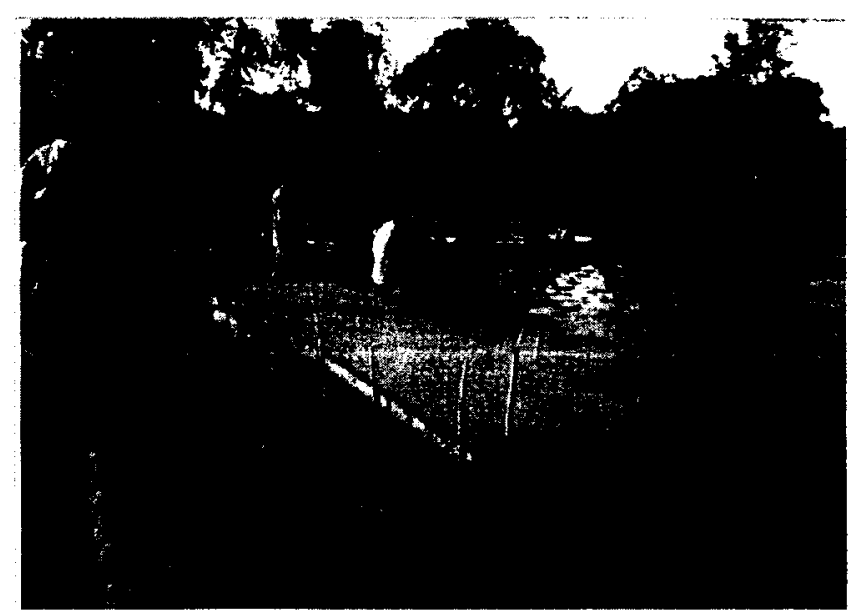

Figure 1. Raised-bed nursery of H.M. Premaratna, Mellawalana, Sri Lanka (Dr. Gamini Batuwitage) 
Rather than raise seedlings in or near the main field, because relatively few seedlings are needed with SRI (it reduces plant populations by $80-90 \%$ because of its much wider spacing of plants), they can be raised anywhere that is convenient, even in the homestead. (One SRI farmer whom I have visited in Tamil Nadu had grown his seedlings on the roof of the family's house). In Eastern Indonesia, where SRI is spreading rapidly with support from Nippon Koei, raising seedlings is commonly done on small trays, which are easily transported to fields (Figures 2 and 3). Seedlings can even be raised on banana leaves.
Some Indian farmers are raising their seedlings in indented plastic trays which can be carried to the fields and from which the young seedlings can be transplanted easily. With this technique, roots are growing downward naturally in the plug of soil, so there is no trauma to roots when the plant is removed. A seedling-raising methodology using mats developed by IRRI can also be adapted appropriately to SRI (http://www.irri.org/irrc/streams/mat\%20nursery.asp).

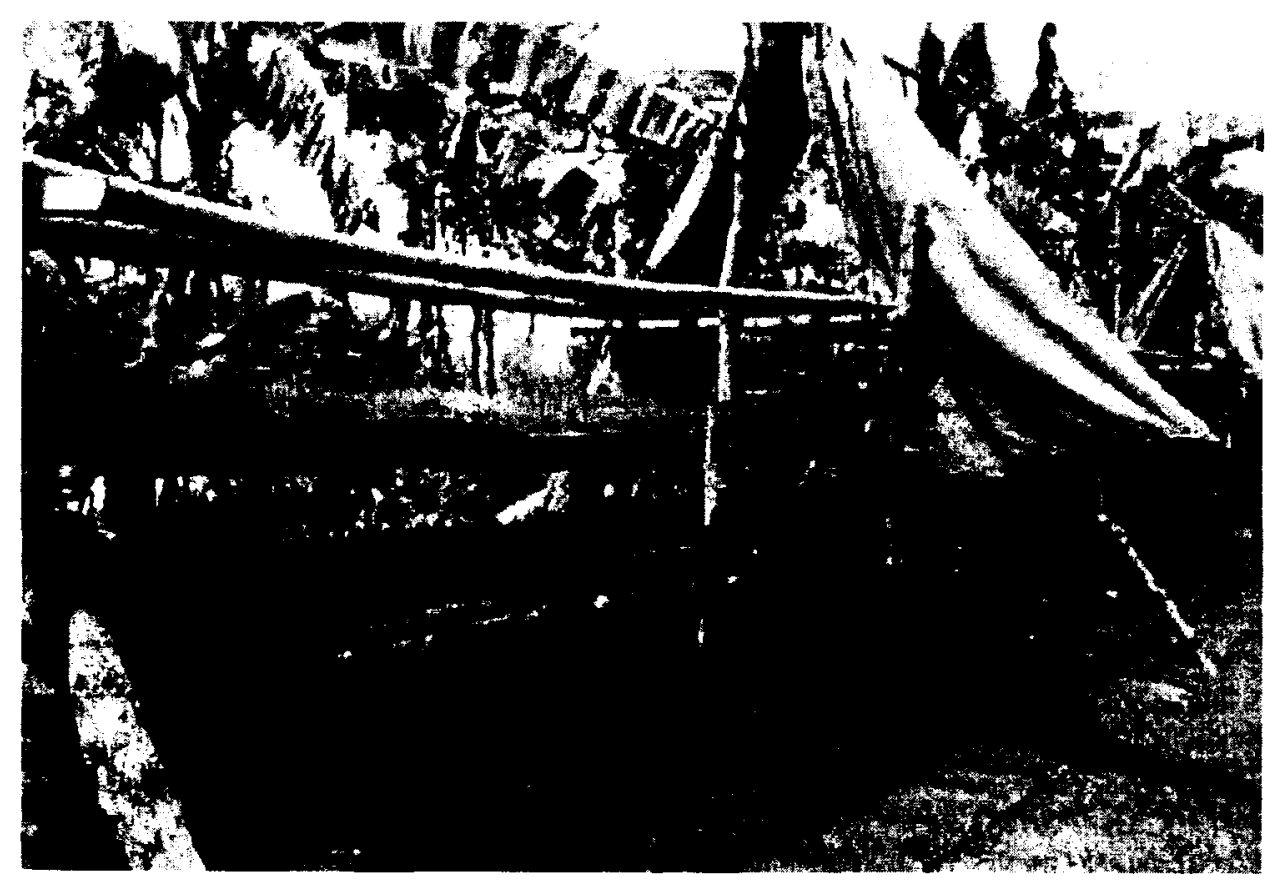

Figure 2. SRI seedlings grown on small trays in racks for transplanting in Eastern Indonesia (Shichi Sato, Nippon Koei DISIMP Office, Jakarta)

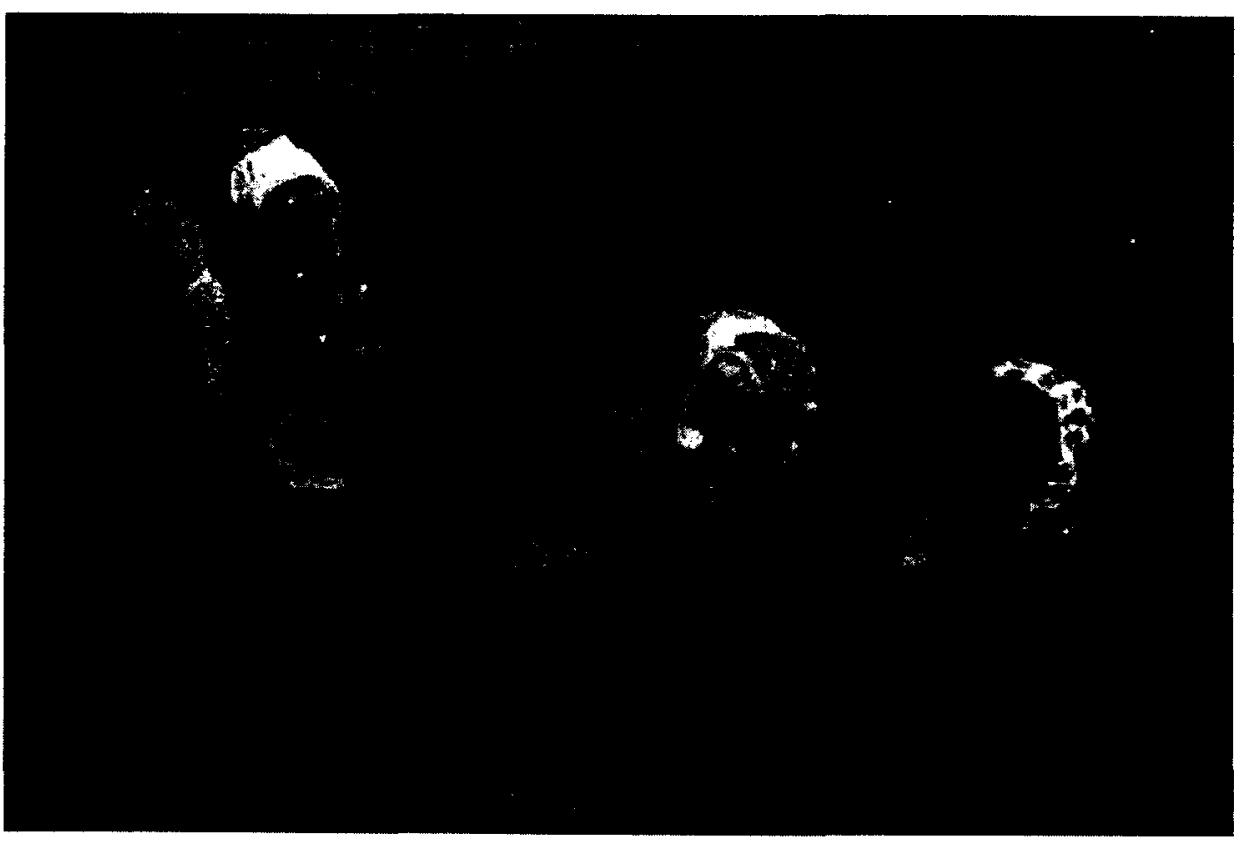

Figure 3. Transplanting young seedlings, carried to field on trays (Shuichi Sato) 


\section{Marking fields for transplanting}

The most visible difference between conventional and SRI cultivation is the planting of single plants in a square pattern for SRI. This ensures that all plants have good and uniform exposure to sunlight and air, with ample room for root growth underground. Also, spacing uniformly in both directions makes it possible for mechanical weeding to be done in two, perpendicular directions. Fr. De Laulanié initially used strings tied to sticks or pegs spaced $25 \mathrm{~cm}$ apart along the edge of paddy fields, facilitating transplanting in a precise grid pattern. An adaptation of this in Tripura state of India has been to use a bamboo rod instead (Figure 4), while in Iraq, a simple board with nails driven into it helps transplanters maintain even spacing.

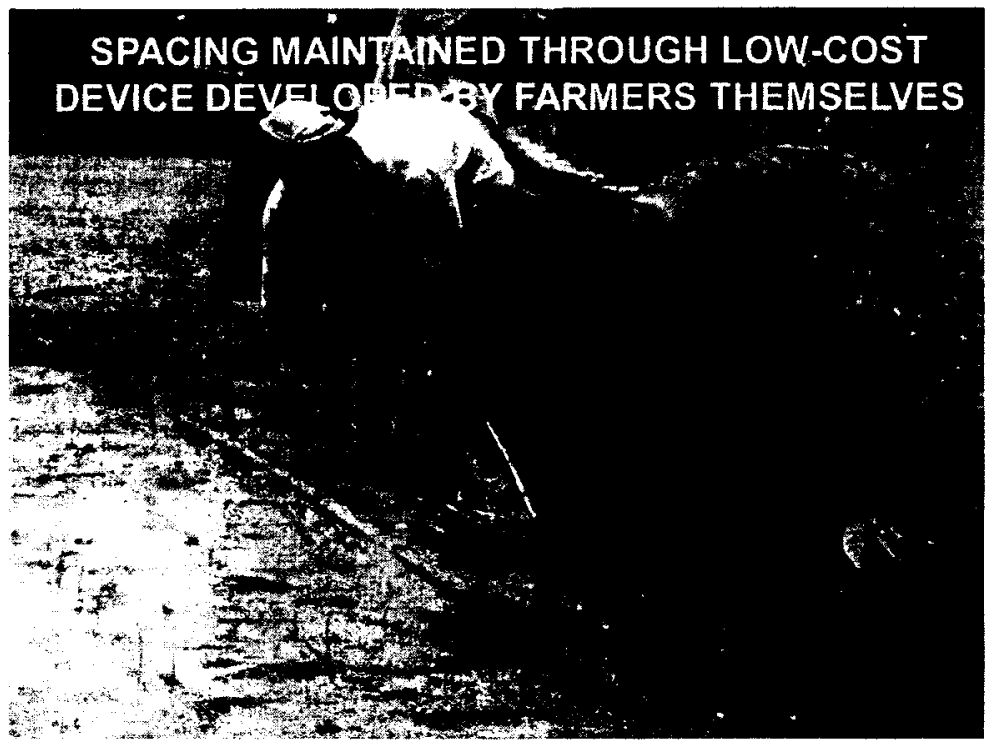

Figure 4. Farmer adaptation in Tripura state of India, using a bamboo stick instead of a string to maintain uniform $25 \times 25 \mathrm{~cm}$ spacing (Baharul Majumder, Dept. of Agriculture, Agartala)

Some farmers in Madagascar and India have, on their own, constructed wooden rake-markers (called a rayonneur in French) with its 'teeth' spaced $25 \mathrm{~cm}$ apart, or wider. These devices can be pulled along the surface of a leveled and muddy field to score parallel lines onto the surface which guide transplanters (Figure 5). If the soil is too saturated, the lines made by the rake-marker do not remain visible. So this method not only speeds up transplanting; it also gives farmers a simple way to assess the viscosity of the soil, to know when it is suitable for SRI transplanting.

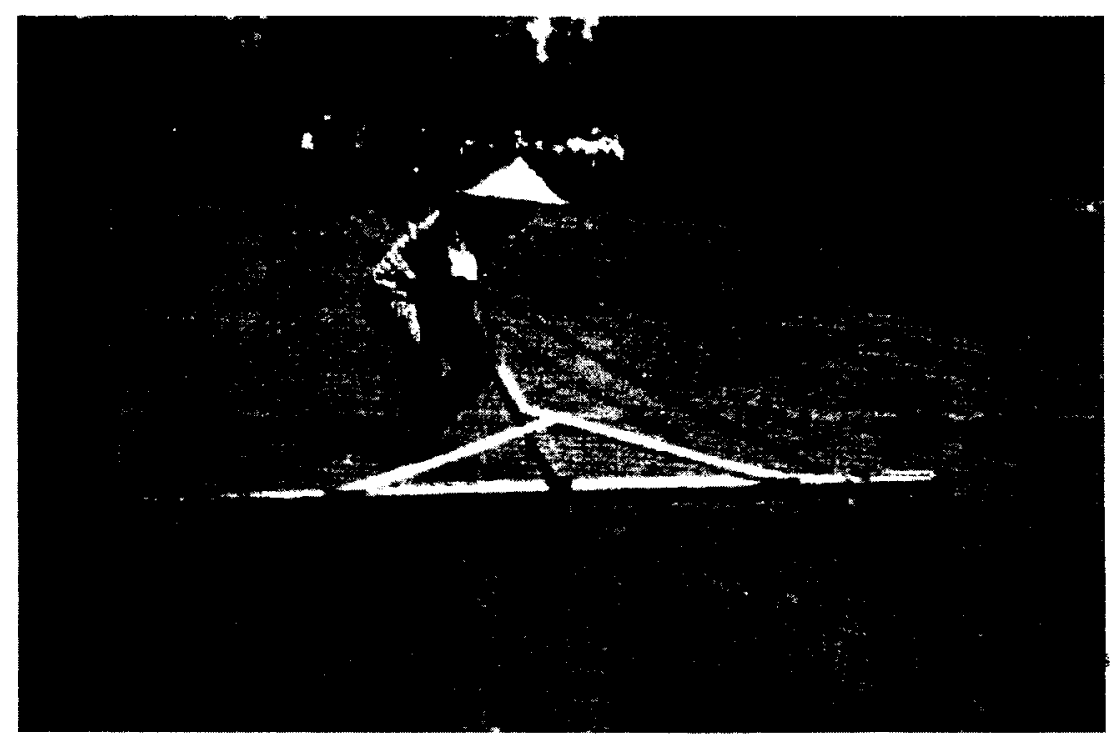

Figure 5. Farmer in Lombok, Indonesia using rake-marker to mark parallel lines on a muddied field. The next step is to draw the rake across the field in a perpendicular direction to make a grid (Shuichi Sato, Nippon Koei DISIMP team, Jakarta) 
Farmers in India have developed a roller-marker, inspired by the simple roller that households use to mark rice-flour patterns around the windows and doorways of their houses at Diwali festival time. This lays down a perfectly square pattern on the surface of their fields very quickly (Figure 6). This saves even more labor time and cost than a rake-marker. Several researchers at the KVK extension center in Madurai, Tamil Nadu state, India have evaluated trapezoidal and triangular patterns marked onto fields with a special roller (http://ciifad.cornell.edu/sri/ conferences/2irc 1006/inZigzagPstr.jpeg). They report that these alternative spatial relationships can give 13-25\% greater tillering compared to a square pattern.

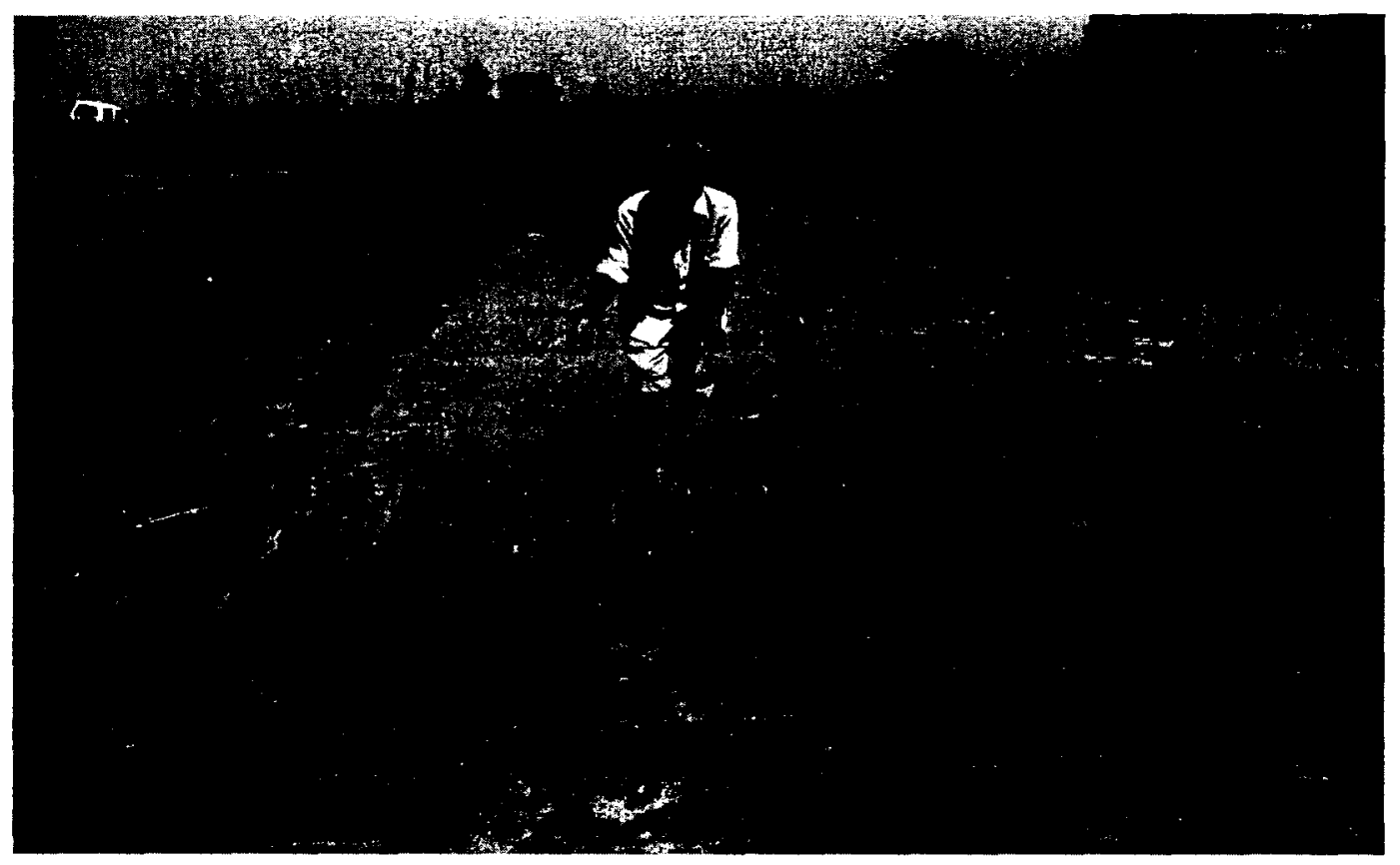

Figure 6. Farmer using roller-marker to prepare field for SRI transplanting in Punjab state of India (Dr. Amrik Singh, ATMA, Gurdaspur)

Another method for marking that I observed on a visit to Tripura state in India is to stretch an elastic rope across the full length or breadth of a field that has been made to have muddy soil. While two persons hold down both ends of the rope at the edges of the field, a third person lifts the tightly-stretched rope at its middle, to chest height, and snaps it back into the soil. This makes a straight line across the length (or width) of the field. The rope is then moved 25 cm to make another line parallel to the first. By stretching the elastic rope across the field, and then snapping it -- and then doing the same thing perpendicularly -- lines can be imprinted on the muddy soil to form a grid pattern, very quickly according to farmers. All of these adaptations improve upon the original strings-and-sticks technique introduced in Madagascar.

\section{Crop establishment}

Transplanting by hand is the norm for paddy rice in most countries, although direct-seeding is being introduced into SRI cultivation in some places. Transplanting very young seedlings (8-12 days old) carefully and precisely by hand appears to give the best crop results. However, this requires a significant labor time. It turns out that transplanting can be done by machine if a mechanical transplanter can be designed and operated consistent with
SRI principles and practice -- and if rice seedlings can be grown in a way that accommodates mechanical handling.

Oscar Montero, a Costa Rican farmer who became interested in SRI for its environmental as well as its economic benefits, has spent three years experimenting with and modifying a transplanting machine manufactured in Asia. In his country, agricultural labor is scarce and expensive, so any labor-intensive activity is difficult to adopt. Montero made the machine (Figure 7) able to transplant 10-day seedlings, most of the time singly, at a spacing of $22 \times 30 \mathrm{~cm}$. The seedlings are grown on planting trays, with the seeds sown in organic 'mats' that can be rolled up and from which the seedlings can be extracted mechanically for transplanting. The substrate for the mats is controlled-combustion rice hulls obtained from the ovens in which paddy has been dried. Montero's yield was 8 t/ha in 2008, achieved with reduced labor inputs requirements. This should make SICA (the name for SRI in Latin America) more attractive in Costa Rica and other countries where labor availability and cost can be constraints for adoption. More information can be obtained at http://ciifad.cornell.edu/sri/countries/costarica/index.html A mat of young seedlings ready for mechanical transplanting is shown in Figure 8. 


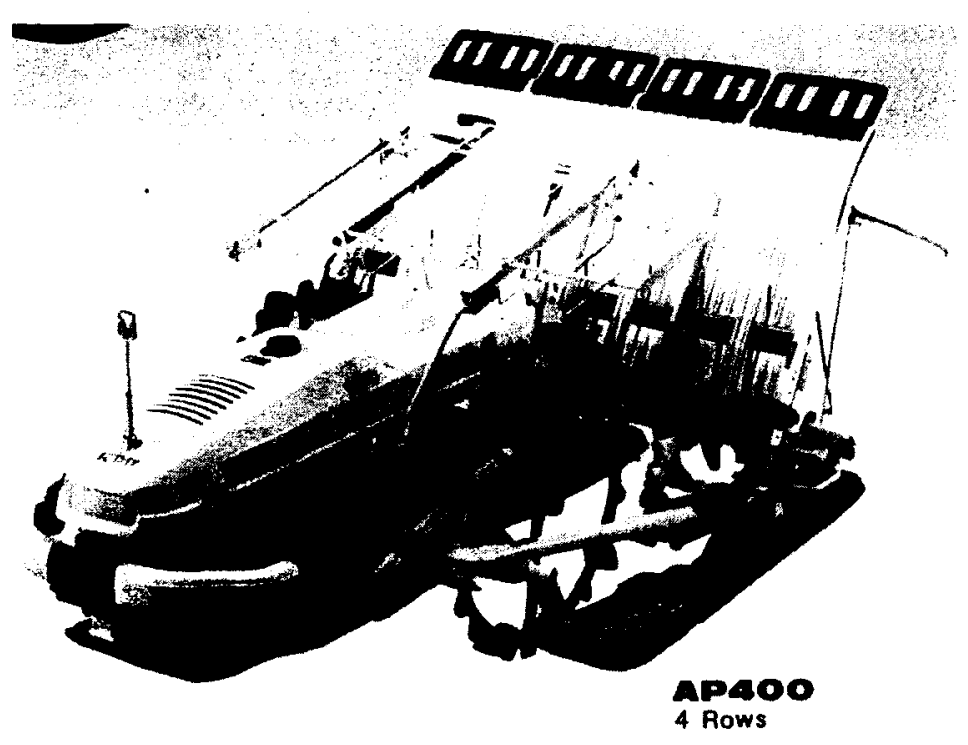

Figure 7. The Yanmar AP400 mechanical rice transplanter modified for SRI use in Costa Rica

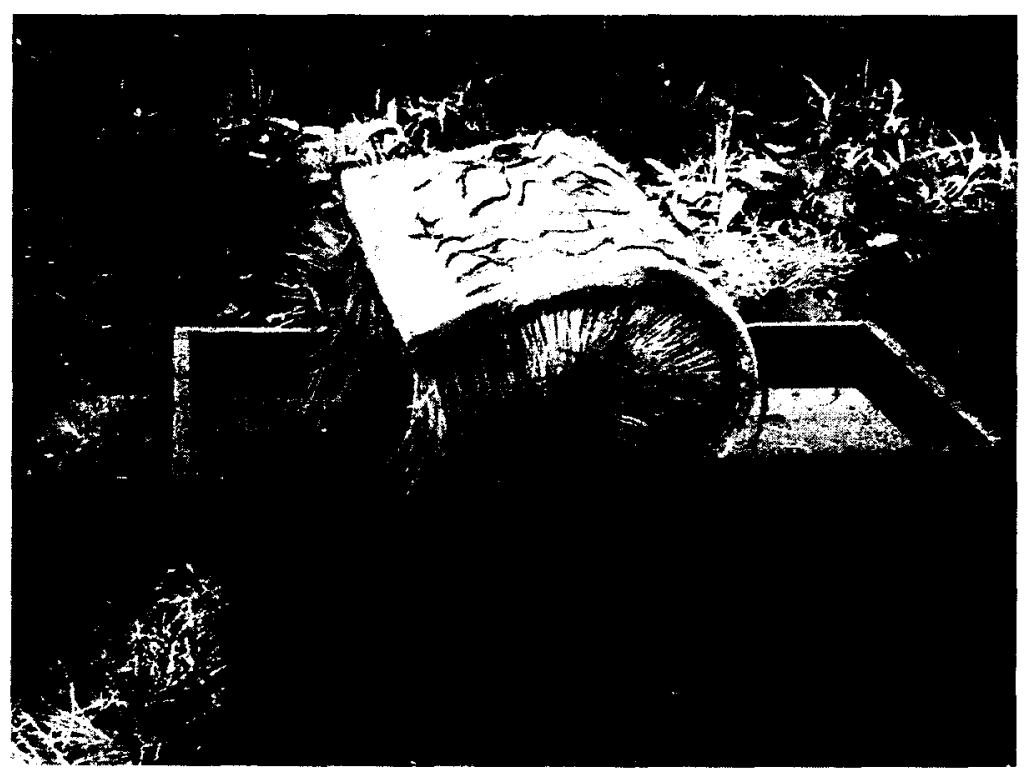

Figure 8. Ten-day seedlings raised in a mat ready for mechanical transplanting (Oscar Montero, Costa Rica)

There are a number of direct-seeding variants of SRI which can save farmers the cost and effort of establishing and operating a nursery and then of transplanting seedlings by hand. One farmer in System ' $H$ ' of the Mahaweli System in Sri Lanka, Ariyaratna Subasinghe, has devised an alternative system that involves broadcasting germinated seed on a puddled (muddy) paddy field. $\mathrm{He}$ does this at a rate of $25 \mathrm{~kg}$ of seed per hectare, five times the rate recommended with 'normal' SRI for transplanted seedlings. When the tiny rice plants coming up in the field are 10 days old, he 'weeds' his field with a rotary weeder as if he had transplanted single seedlings into the field at
$25 \times 25 \mathrm{~cm}$ spacing. To speed up this weeding and make it easier physically, Subasinghe has built a motorized weeder, shown in below (Figure 13).

This 'weeding' operation, which Subasinghe would have done in any case, drastically thins out of the crop, eliminating about $80 \%$ of the plants, leaving usually just one plant at the intersections of his perpendicular weeder transects. Sometimes there is no plant in a space, and sometimes 2 seedlings or even 3; so the distribution of plants across the field is not as precise as with transplanting. However, this method can give a yield of 7.5 tha according to Subasinghe. By 'sacrificing' $20 \mathrm{~kg}$ of 
seed, he can greatly reduce his labor requirements. According to an evaluation by researchers at Tamil Nadu Agricultural University, this method reduces labor by $40 \%$ while giving comparable yield levels as with transplanting (http://ciifad.cornell.edu/sri/countries/india/intnramasapster 06.pdf). This system could over time become the most common method for SRI crop establishment because of its great labor-saving possibilities.

Other forms of direct seeding are being introduced and evaluated by farmers and/or researchers working with them, making adaptations of SRI in places as diverse as
Cuba, India (Figure 9) and Thailand (Figure 10). Over time, I think it is likely that direct-seeding will supersede transplanting as the main method of SRI crop establishment, or with mechanical transplanting becoming widespread. There is no requirement that seedlings be transplanting to obtain benefits from SRI principles and insights rather SRI advises that any trauma and stress that could degrade plant roots should be avoided, with the corollary that if one transplants, this should be done before the start of the 4 th phyllochron to achieve greater tillering and root proliferation (Stoop et al., 2002).

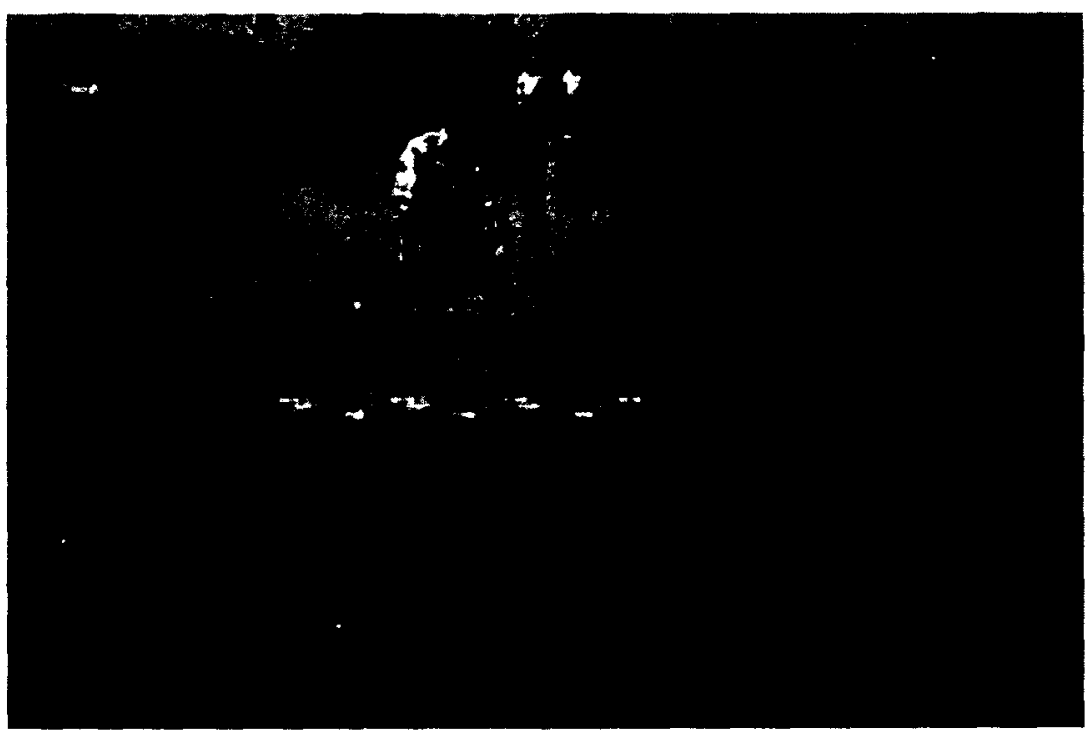

Figure 9. Direct-seeder developed for SRI by KVK extension center in Chittoor, Andhra Pradesh, India (Dr. Bala Husein Reddy, Chittoor KVK)

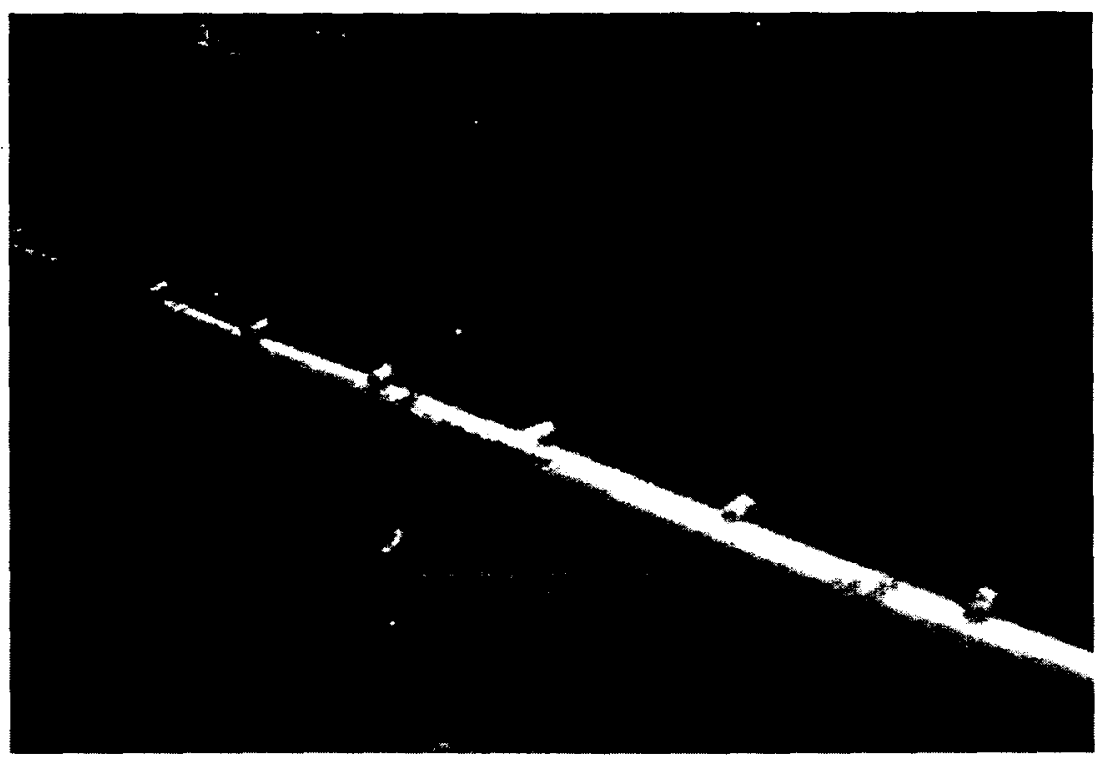

Figure 10. Section of SRI seeder being built by farmers from plastic materials in Roi-et Province, Thailand (Dr. Prabhat Kumar, Asian Institute of Technology) 
Along with direct-seeding, I expect that over time, raised beds will also become a prominent alternative method of soil management for SRI over time, together with zero-tillage. One of the most innovative SRI farmers in China has adapted SRI to raised-bed/zero-tillage cultivation in Sichuan province, getting a yield calculated by the Provincial Department of Agriculture to be 13.4 tha (Figure 11). Liu also rotates his SRI rice with a potato crop, this crop being reported by a number of farmers to be a good intercrop for SRI, perhaps because of the soil aeration which is involved with potato production.

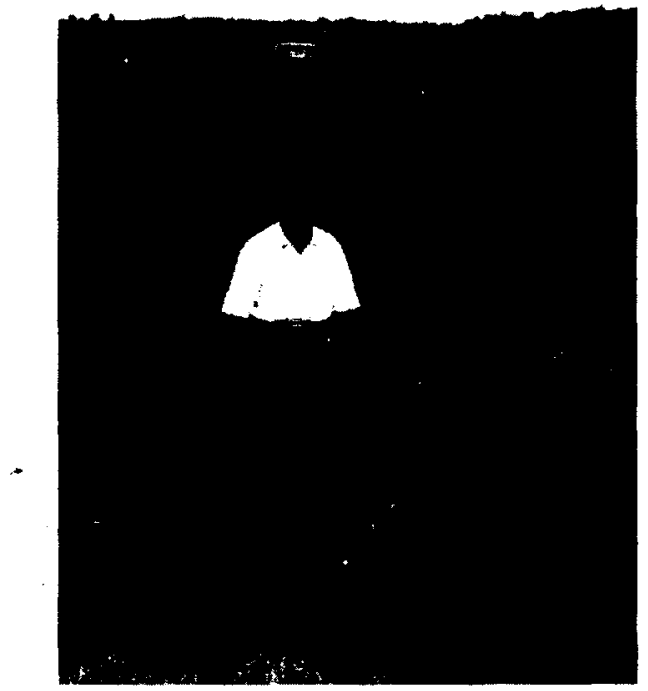

Figure 11. Liu Zhibin, Meishan, Sichuan province, China, standing in section of an SRI field recently harvested, in which he had transplanted seedlings onto raised beds with zerotillage (N. Uphoff)

Another innovative Chinese SRI farmer in $\mathrm{Bu}$ Tou village, Nie Fu-qui, living in Tian Tai country in Zhejiang province, has combined mechanized direct-seeding with zero-tillage, getting a yield over 11 tha with reduced labor costs

(http://ciifad.cornell.edu/sri/countries/china/index.html -second item under 2005 Updates). The implement that $\mathrm{Nie}$ designed and built for direct-seeding places single rice seeds at $23.3 \times 30.5 \mathrm{~cm}$ for this alternative method of SRI crop establishment. ${ }^{4}$

Another method for SRI crop establishment still under development by Gopal Swaminathan in Tamil Nadu state of India forms the soil mechanically to create ridges and furrows. Two rows of direct-seeded rice are planted on each ridge, maintaining wide spacing between plants in both directions. Irrigation water is then provided through the furrows that lie between the ridges. This saves water as well as labor. ${ }^{5}$ I have talked with farmers cooperating with CEDAC in Cambodia who were experimenting with their own raised-bed/zero-tillage SRI adaptations. They were pleased with their results, but were still undecided between direct seeding vs. transplanting. Further experimentation and evaluation on these alternatives, with various adaptations, will surely continue for some years, and there will be a variety of methods for crop establishment, affected by labor and machinery availability, soil and climate conditions, etc.

\section{Means of weed control}

Some years ago, a mechanical hand weeder was developed in Japan that was taken up by some farmers in many countries to facilitate weed removal between rows. It has various names and modifications, but is widely known as a rotating hoe (or houe rotative in French). IRRI engineers subsequently developed what is called a cono weeder, which works better, more easily, more quickly, in various soils, especially better for heavy clay soils (Figure 12). Fr. De Laulanié introduced the planting of rice plants in a square pattern into SRI so that a mechanical weeder could be used in perpendicular directions, aerating the soil all around each plant, rather than just between rows.

\footnotetext{
${ }^{3}$ Liu Zhibin developed a 'triangular' method of transplanting SRI seedlings, where there are three plants per hill but in half as many hills (more widely spaced), and with $8.10 \mathrm{~cm}$ between the three plants in a triangular shape. This way the benefits of wide spacing are maintained while plant population is increased by $50 \%$ over conventional square-planted SRI (http://ciifad.cornell.edu/sri/countries/china/cntriang.pdf).

${ }^{4}$ In 2004, using 'standard' SRI practices, Nie achieved a $12 \mathrm{t} / \mathrm{ha}$ yield, the highest in the province. The next year, his rice fields like those of his neighbors were hit by three typhoons during August and September; yet his harvested yield averaged 11.15 tha while most other farmers in his area had serious crop losses from storm damage.

${ }^{5} \mathrm{G}$. Swaminathan has also developed an innovative crop establishment method for SRI to deal with the high summer temperatures and hot sunlight in the Cauvery Delta of Tamil Nadu. He protects the young seedlings from desiccation by the sun and wind by a double transplanting strategy. At 12 days, he first transplants young seedlings from the nursery, $4-5$ each in hills $15 \times 15 \mathrm{~cm}$. Then at 30 days, he re -transplants them as single seedlings, spaced $20-20 \mathrm{~cm}$. This requires more labor, but an assured yield of $7.5 \mathrm{tha}$ more than repays the cost (http://ciifad.comell.edu/sri/countries/india/kadiramangalam,html). The summer climate in the Cauvery Delta is otherwise too stressful for SRI seedlings.
} 

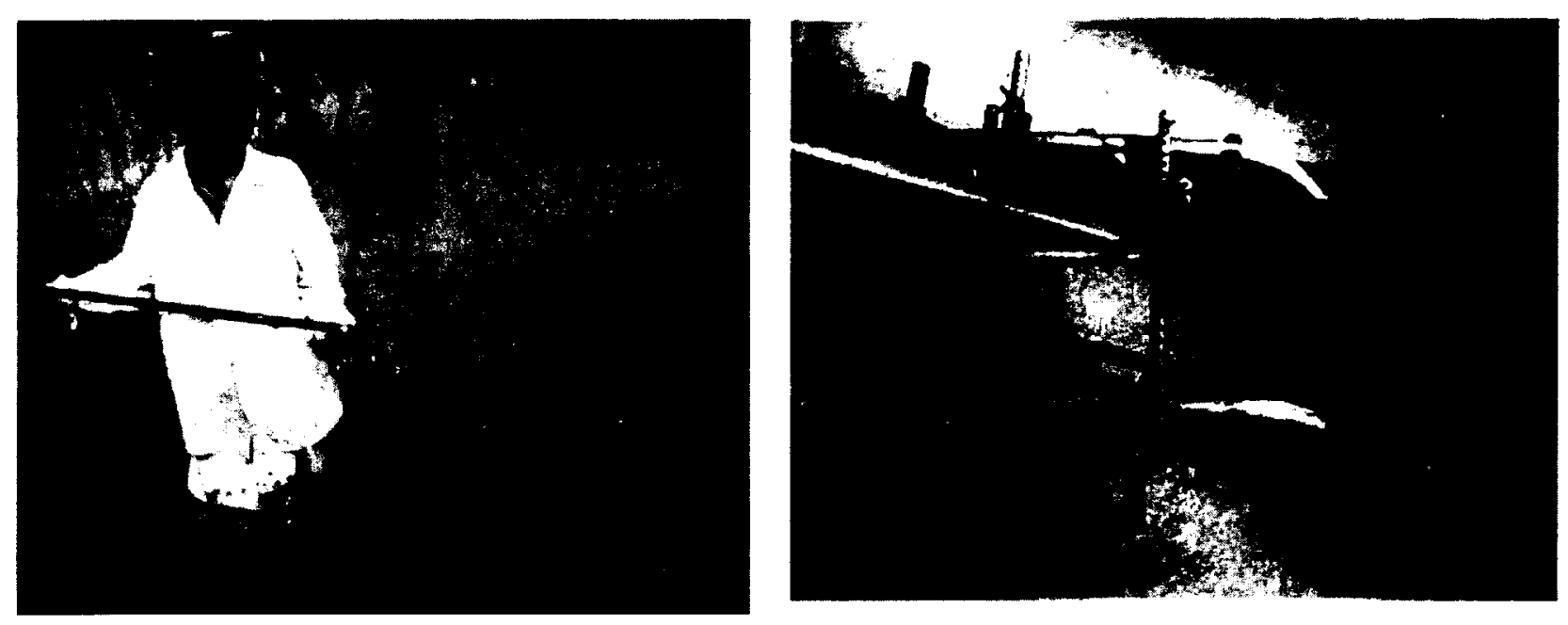

Figure 12. On left, improved cono weeder designed by H.M. Premaratna, Mellawalana, Sri Lanka, and on right, a model made by local engineer in Madagascar to inter-cultivate two rows at a time, with the option of adjusting the cones for wider or narrower inter-row spacings (N. Uphoff)

Farmers in various countries have come up with various versions of the rotating hoe or cono weeder. In Figure 13 we see examples of the range of innovation from a simple home-made weeder constructed for less than $\$ 3$ in Cambodia from local materials (heavy nails, wooden axle, iron rods), to a more expensive motorized weeder in Sri Lanka that enables this farmer to weed and at the same time aerate the soil on his 2-hectare farm not needing to hire any labor.
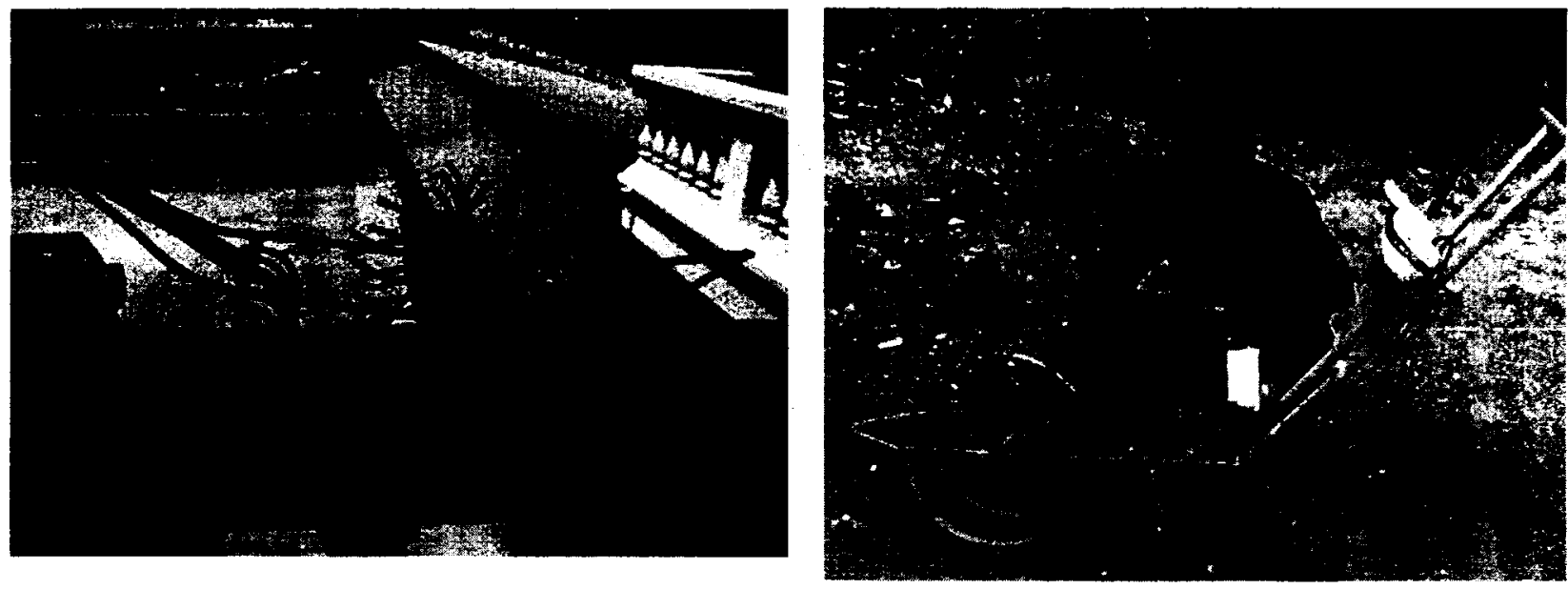

Figure 13. On left, a weeder designed and built by Nong Sovann, Kandol village, Kampoth Speu, Cambodia, from local materials (wooden axle, heavy nails, iron rods) (N. Uphoff); on right, more expensive, motor-powered weeder designed and built by Ariyaratna Subasinghe, System H, Mahaweli project, Sri Lanka (A. Subasinghe)

Other weeder designs have been developed for other situations and needs e.g., a weeder that can cover four rows at the same time, thereby greatly reducing the time and cost required for soil-aerating weeding (Figure 14). For some farmers this kind of implement is too expensive, however.
Working with farmers in Madagascar, Association Tefy Saina has developed a super-simple weeder with no moving parts so that it is very durable, and costs only about $\$ 2$ to make. It requires two persons to operate one to pull on a rope in front, providing power, while other guides the 
toothed board between the rows of plants. Farmers say that it can be pulled up and down the rows quickly enough (and labor costs in Madagascar are relatively low), so that this model is a good alternative to metal weeders, which are more expensive. The weeder on the left in very popular with farmers and costs less than $\$ 10$ in Sri Lanka.
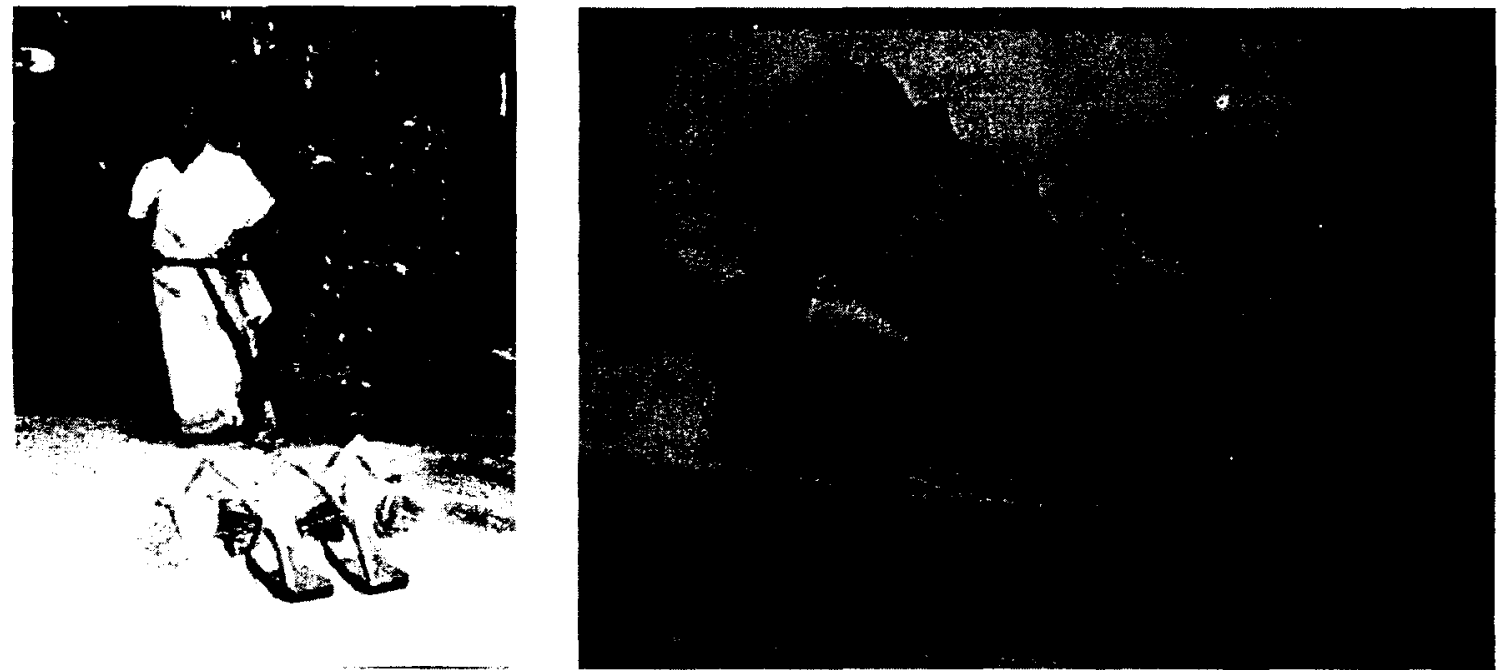

Figure 14. On left, four-row cono weeder developed by Gopal Swaminathan, Kadiramangalam, Cauvery Delta, Tamil Nadu, India (G. Swaminathan);on right, underside of a simple weeder developed by Association Tefy Saina in Madagascar for operation by two persons (Association Tefy Saina)

The simplest weeder I have seen costs only 25 cents to make. Govind Dhakal in Nepal experienced severe weed problems the first time he tried SRI methods. His neighbors thought he would never try them again. But Govind got the idea of constructing a weeder, operated much like a push broom, that required only wood and nails. He found that with such weeders could cut his labor costs as well as control weeds and aerate the soil. With this tool, 4 laborers could weed as much area in a day as 10-12 laborers doing hand weeding.

Still more weeder models could be shown. The purpose of showing here such a variety is to make very evident the diversity and ingenuity of farmers' solutions to an important constraint for SRI (weed growth) when the flooding of fields is not used as a method of weed control. We can see how farmers can and will innovate if the production system offered to them is presented not as a final, finished product for adoption (or turning down), but rather as an opportunity, for which further thought and innovation on their part are expected.

\section{RAINFED SRI}

The System of Rice Intensification was developed for irrigated rice production in Madagascar. But many of the world's poorest households do not have access to irrigated land, needing to support them selves from upland, unirrigated fields. The extrapolation of SRI concepts and methods to such circumstances has been initiated usually by NGOs working closely with farmers. The methods have been worked out with extensive farmer involvement, instead of being devised by 'experts' and then 'extended' to farmers.

In the 1998-99 season, a government rice specialist and university student working with Tefy Saina and
CIIFAD around Ranomafana National Park in Madagascar tried to adapt SRI concepts to rainfed production. They worked directly with farmers on their fields, seeking an alternative to slash-and-burn, tavy cultivation. After clearing a farmer's upland plot without using fire, hills widely spaced $(30 \times 30 \mathrm{~cm})$ were planted with $3-4$ seeds each instead of with whole panicles of rice, as was local practice. Ten days later, each hill was thinned to leave just the most vigorous single plant, and the space between hills was mulched with shredded branches of leguminous plants (tephrosia and crotalaria), with a depth of $7 \mathrm{~cm}$, which settled down to about $5 \mathrm{~cm}$. This conserved soil moisture as well as suppressed weeds. Some chemical fertilizer was used to supplement the compost applied at planting time. With wide spacing and very few plants, a yield of $4.02 \mathrm{t} / \mathrm{ha}$ was achieved from replicated trials, 2.5 to 5 times more than the yield usually produced with shifting cultivation methods, 0.8-1.5 t/ha (Barison, 1999). While more labor was required, the time invested was better remunerated per day of work than in traditional shifting cultivation.

This idea was taken by Robert Gasparillo of the Philippine NGO, Broader Initiatives for Negros Development (BIND), who learned about it from Barison at the first international SRI conference held in China in 2002. The next year, he set out 20 trials with 5 spacings and 4 replications $\left(4,000 \mathrm{~m}^{2}\right.$ total area) on farmers' fields in Negros Occidental province. The average for the whole area, without any irrigation, was $7.2 \mathrm{t} / \mathrm{ha}$-- instead of more typical yield of $3 \mathrm{t} / \mathrm{ha}$. The best spacing $(20 \times 40 \mathrm{~cm})$ gave a yield of $7.7 \mathrm{t} / \mathrm{ha}$, without irrigation, just with rainfall (Gasparillo et al, 2003).

Metta Development Foundation, an indigenous NGO working in northern Myanmar, began adapting SRI concepts to rainfed rice cultivation there starting in 2001. It used Farmer Field School training methods where farmers 
are actively engaged in the evaluation and adaptation of new methods. Within three years, over 5,000 farmers had been trained in SRI methods, and over 20,000 farmers were using the new methods by 2004 , thanks to farmer-to-farmer dissemination at village level.

Longitudinal studies showed that within three years of training one-third of the farmers in a village through FFS methods, almost $100 \%$ of the farmers there were using the improved practices. By 2008 , it was estimated that over 50,000 farmers were using rainfed SRI methods. On plots managed by FFS participants for learning and demonstration, where SRI methods were used mostly as recommended, yields were 6 to $7 \mathrm{t} /$ ha, instead of the usual 2 tha in the region. On farmers' fields, with incomplete use of SRI methods, the average paddy yield for a large number of farmers monitored $(\mathrm{N}=612)$ was over $4 \mathrm{t} / \mathrm{ha}$, more than doubling previous yields (Kabir and Uphoff, 2007).

The Indian NGO PRADAN started introducing SRI in rainfed areas of the Eastern Gangetic Plains, where poverty is greater than many other parts of the country, in 2003. The first year PRADAN staff could get only 4 farmers to try out the new methods. Next year, 150 farmers were willing to take up the methods, with a $67 \%$ increase in net income per hectare calculated by an IWMI-India Programme research team, even with half of the farmers studied having experienced severe drought (Sinha and Talati, 2007). By 2006, the number of SRI users reached 6,500 , with average yields of $7.2 \mathrm{t} / \mathrm{ha}$ where yields had been $2-3 \mathrm{t} / \mathrm{ha}$ previously (PRADAN, 2007). These results are cited from four countries to show how farmers working with NGOs or researchers under unfavorable agroecological conditions can make fairly complex transformations of their farming systems under the influence of new ideas, with positive results.

\section{REFERENCES}

Anthofer, J. 2004. Evaluation of the System of Rice Intensification (SRI) in Cambodia. Report prepared for GTZ, Phnom Penh. (http://www.tropentag.de/ 2004/abstracts/full/399.pdf).

Barison, J. 1999. Adaptation of SRI Methods to Upland Rice. CIIFAD Annual Report, 1998-99, 103, Cornell International Institute for Food, Agriculture and Development (CIIFAD), Ithaca, NY.

Chaboussou, F. 2004. Healthy Crops: A New Agricultural Revolution. Jon Anderson, Charnley, UK.

Gasparillo, R., R. Naragdao, E.A. Judilla, J. Tana and M. Magsalin. 2003. Growth and yield response of traditional upland rice on difference distance of planting using Azucaena variety. Broader Initiatives for Negros Development, Bacalod City. (http://ciifad.cornell.edu/sri/countries/philippines/binu prst.pdf).

Kabir, H. and N. Uphoff. 2007. Results of disseminating the System of Rice Intensification (SRI) with farmer field school methods in northern Myanmar. Experimental Agriculture, 43:4.
Laulanié, H. 1993. Le système de riziculture intensive malgache.Tropicultura 11: 110-114.

Laulanié, H. 2003. Le Riz à Madagascar: Un dèveloppement en dialogue avec les paysans, Editions Karthala, Paris.

Li X-Y., Xu X., and Li H. 2004. A socio-economic assessment of the System of Rice Intensification (SRI): A case study from Xinsheng Village, Jianyang County, Sichuan Province. Center for Integrated Agricultural Development, China Agricultural University, Beijing. (http://ciifad.comell.edu/sri/ countries/china/cnciadeng.pdf).

Moser, C.M. and C.B. Barrett. 2003. The disappointing adoption dynamics of a yield-increasing, low externalinput technology: The case of SRI in Madagascar. Agricultural Systems 76: 1085-1100.

PRADAN. 2007. Report on SRI Experience in Purulia District, West Bengal, to IWMI for 2006 Kharif Season, $2^{\text {nd }}$ Report, April. (http://ciifad.cornell.edu/ sri/countries/india/inpuruliakh0607.pdf).

Randriamiharisoa, R., J. Barison and N. Uphoff. 2006. Soil biological contributions to the System of Rice Production, in N. Uphoff et al. (eds.), Biological Approaches to Sustainable Soil Systems, 409-424, CRC Press, Boca Raton, FL.

Sato, S. and N. Uphoff. 2007. A review of on-farm evaluations of system of rice intensification methods in Eastern Indonesia. CAB Reviews: Perspectives in Agriculture, Veterinary Science, Nutrition and Natural Resources, 2.

Satyanarayana, A., T.M. Thiyagarajan and N. Uphoff. 2006. Opportunities for saving water with higher yield from the System of Rice Intensification. Irrigation Science, 38:1, 99-115.

Sinha, S.K. and J. Talati. 2007. Productivity impacts of the system of rice intensification (SRI): A case study in West Bengal, India. Agricultural Water Management 87: 55-60.

Stoop, W., N. Uphoff and A. Kassam. 2002. A review of agricultural research issues raised by the System of Rice Intensification (SRI) from Madagascar: Opportunities for improving farming systems for resource-poor farmers. Agricultural Systems 71:249274.

Uphoff, N. 2005. The development of the System of Rice Intensification, in J. Gonsalves et al. (eds.), Participatory Research and Development for Sustainable Agriculture and Rural Development, Vol. 3, 119-125, International Potato Center-UPWARD and International Development Research Centre, Ottawa.

Uphoff, N. 2007. Reducing the vulnerability of rural households through agroecological practices: Considering the System of Rice Intensification (SRI), Mondes en Développement, 35: 85-100. 